\title{
Hip Replacement in Ankylosing Spondylitis
}

\section{Patients with Advanced Hip Involvement: Factors Associated with Bilateral Total Hip Arthroplasty}

\author{
Liangliang $\mathrm{Li}^{\mathrm{I}-3}$ \\ Jun $\mathrm{Fu}^{2}$ \\ Chi Xu (iD) ${ }^{2}$ \\ Ming $\mathrm{Ni}^{2}$ \\ Wei Chai ${ }^{2}$ \\ Libo $\mathrm{Hao}^{2}$ \\ Yonggang Zhou ${ }^{2}$ \\ Jiying Chen ${ }^{2}$
}

'Medical School of Chinese PLA, Beijing, People's Republic of China; ${ }^{2}$ Department of Orthopedics, The First Medical

Centre, Chinese PLA General Hospital, Beijing, People's Republic of China;

${ }^{3}$ Department of Orthopedics, The Second Hospital of Shanxi Medical University, Taiyuan, Shanxi, People's Republic of China
Correspondence: Jiying Chen; Libo Hao Department of Orthopedics, The First Medical Centre, Chinese PLA General Hospital, No. 28 Fuxing Road, Haidian District, Beijing, I00853, People's Republic of China

Tel +86 I390I078832;

$\mathrm{Tel}+8613901078832$

Fax +8601068216336

Email chenjiying_30।@I63.com;

haolibo30I@sina.com
Background: This study aimed to compare the clinical data of ankylosing spondylitis (AS) patients who underwent unilateral and bilateral total hip arthroplasty (THA) due to advanced hip involvement. Furthermore, to determine the factors associated with bilateral THA.

Methods: Utilizing a single-institution database, we selected 373 consecutive AS patients undergoing primary THA from 2012 to 2017 and compared the clinical characteristics and anti-tumor necrosis factor (TNF) therapy of the patients who underwent unilateral and bilateral THA. Logistic regression was used to identify factors associated with bilateral THA. Results: Bilateral THA was performed in $67.3 \%(n=251)$ of the patients. Male patients had a higher frequency of undergoing bilateral THA compared with female ones $(\mathrm{P}<0.05)$. The proportion of the patients who had bilateral onset in hips, administration of TNF inhibitors, flexion contracture in the hip, and a BASRI-hip score of 4 was significantly higher in patients with bilateral THA than that with unilateral THA $(\mathrm{P}<0.05)$. Patients with bilateral THA experienced longer disease duration than those with unilateral THA $(\mathrm{P}<0.05)$. The results of the logistic regression showed that factors related to bilateral THA were bilateral onset in hips, administration of TNF inhibitors, a BASRI-hip score of 4, and an erythrocyte sedimentation rate (ESR) level $(\mathrm{P}<0.05)$.

Conclusion: Bilateral THA is more common in AS patients with advanced hip involvement. Bilateral onset in hips, a BASRI-hip score of 4, and a higher level of ESR are risk factors associated with bilateral THA, while anti-TNF therapy is a protective factor reducing the progression of hip involvement to bilateral THA.

Keywords: ankylosing spondylitis, hip involvement, bilateral total hip arthroplasty, antiTNF therapy

\section{Introduction}

Ankylosing spondylitis (AS) is a chronic autoimmune disease characterized by mainly affecting the axial skeleton, and peripheral joints are involved in some patients during the course of the disease. ${ }^{1}$ Hip involvement is a particular concern in AS and commonly leads to severe functional impairment in the patients, due to hip serving as the role of the central joint connecting the axial skeleton and the lower limb. ${ }^{2-4}$ For AS patients with the end-stage hip disease, total hip arthroplasty (THA) has been shown to alleviate pain and improve function effectively. ${ }^{5}$ Generally, these patients vary in their severity and progressive speed of hip involvement, according to which undergoing unilateral or bilateral THA is determined. 
Obviously, bilateral THA increases the possibility of revision surgery for individuals due to the limited life span of hip prostheses. Until now, most of the studies on bilateral THA have focused on surgical techniques, prosthesis selection strategies, and postoperative clinical outcomes. ${ }^{6}$ However, there is a paucity of data on investigating why the end-stage hip involvement is bilateral in some patients while unilateral in others. In this study, we considered bilateral THA to be an objective proxy for more severe end-stage hip involvement compared with unilateral THA. Therefore, we wished, by determining the factors related to bilateral THA, to reduce the amount or postpone the time of performing THA in AS patients.

\section{Materials and Methods}

\section{Patient Selection and Data Sources}

This is a single-institution, retrospective study, which investigated 405 consecutive AS patients with advanced hip involvement who underwent primary THA in the orthopaedic department of our hospital from January 2012 to December 2017. This study was approved by the local ethics committee of Chinese PLA General Hospital. Research data on hip involvement of the patients were obtained from medical records and radiographs. All patients had a confirmed diagnosis of AS in accordance with the 1984 modified New York criteria ${ }^{7}$ and had definite indications of requiring THA. ${ }^{5}$ Those with (1) a history of hip trauma or operation in hips (7 cases), (2) spine and hip procedure being performed during the same admission (3 cases), (3) coagulation disorders that may cause hip arthritis ( 3 cases), and (4) incomplete medical data (11 cases) were excluded. Ultimately, 373 AS patients with advanced hip involvement were enrolled in this study.

\section{Grouping Criteria and Research Data}

The patients were divided into two groups by THA being performed unilaterally $(n=122)$ or bilaterally $(n=251)$. The unilateral THA was defined as performing THA in the involved hip and not performing THA in the contralateral hip for at least one year. The bilateral THA was defined as performing THA in both hips. The comparative data between the two groups consists of demographics, clinical characteristics, and preoperative laboratory values. The clinical characteristics comprised age at onset (time of symptom onset in the hip), bilateral onset in hips (initial pain occurred bilaterally in the hips), disease duration (from onset to THA), administration of tumor necrosis factor (TNF) inhibitors (having a history of using TNF inhibitors), family history of rheumatism (having rheumatoid diseases in any immediate family members), smoking history (accumulated smoking for 6 months), and flexion contracture in the hip (position of hip contracture and stiffness in supine position). Preoperative laboratory values, including erythrocyte sedimentation rate (ESR) and C-reactive protein (CRP) level, were available for assessing the inflammation levels of AS patients.

\section{Radiological Assessments}

The same imaging protocol was used for preoperative anteroposterior pelvic radiographs in the patients. The severity of radiographic hip involvement was evaluated by using the Bath Ankylosing Spondylitis Radiology Hip Index (BASRI-hip) scoring system, which is graded on a scale of $0-4$ (0, no change; 1 , suspicious: focal joint space narrowing; 2 , mild: circumferential joint space narrowing $>2 \mathrm{~mm} ; 3$, moderate: circumferential joint space narrowing $\leq 2 \mathrm{~mm}$ or bone-on-bone apposition of $<2 \mathrm{~cm}$; 4 , severe: bone deformity or bone-on-bone apposition of $\geq 2 \mathrm{~cm}) .{ }^{8}$ The BASRI-hip was scored by two trained readers according to preoperative anteroposterior pelvic radiographs. If the score differed between the two readers, the final score was determined by another experienced senior surgeon. Patients with a BASRI-hip score $\geq 2$ were deemed as having radiographic hip involvement.

\section{Statistical Analysis}

The non-normally distributed continuous variables were expressed as medians (minimum to maximum) and compared by the Mann-Whitney $U$-test. Categorical and dichotomous variables were compared by Chi-squared or Fisher's exact tests. A univariate analysis was performed to assess whether each variable of interest was associated with bilateral THA. Then, a logistic regression analysis was used for the assessment of risk factors identified as significant in the univariate analysis or other variables being possibly meaningful, and the odds ratios (ORs) with 95\% confidence intervals (CIs) were determined. All statistical analyses were performed using IBM SPSS statistics for windows, version 25.0 (IBM, Armonk, NY, USA). $\mathrm{P}<0.05$ was considered to indicate statistical significance.

\section{Results}

The baseline characteristics of AS patients with advanced hip involvement are presented in Table 1. The median age 
Table I Baseline Characteristics of AS Patients with Advanced Hip Involvement

\begin{tabular}{|c|c|c|}
\hline & Values & Range \\
\hline \multicolumn{3}{|l|}{ Demographics } \\
\hline Age at surgery (years) & 32 & 19 to 67 \\
\hline Male $(n, \%)$ & $218(89.7 \%)$ & \\
\hline BMI $\left(\mathrm{kg} / \mathrm{m}^{2}\right)$ & 22.50 & 11.87 to 41.62 \\
\hline \multicolumn{3}{|l|}{ Clinical characteristics } \\
\hline Age at onset (years) & 18 & 5 to 56 \\
\hline Bilateral onset in hips (n, \%) & $238(63.8 \%)$ & \\
\hline Disease duration (years) & 10.5 & 0.5 to 40.3 \\
\hline Administration of TNF inhibitors ( $n, \%)$ & $36(9.7 \%)$ & \\
\hline Family history of rheumatism (n, \%) & $39(10.5 \%)$ & \\
\hline Smoking history $(\mathrm{n}, \%)$ & $53(14.2 \%)$ & \\
\hline \multicolumn{3}{|l|}{ BASRI-hip (No. of cases in hips) } \\
\hline $0(n, \%)$ & $20(2.7 \%)$ & \\
\hline $\mathrm{I}(\mathrm{n}, \%)$ & $39(5.2 \%)$ & \\
\hline $2(n, \%)$ & $37(4.9 \%)$ & \\
\hline $3(n, \%)$ & $313(42.0 \%)$ & \\
\hline $4(n, \%)$ & $337(45.2 \%)$ & \\
\hline Bilateral THA $(n, \%)$ & $25 \mathrm{I}(67.3 \%)$ & \\
\hline \multicolumn{3}{|l|}{ Preoperative laboratory values } \\
\hline $\operatorname{ESR}(\mathrm{mm} / \mathrm{h})$ & 17 & I to 108 \\
\hline $\mathrm{CRP}(\mathrm{mg} / \mathrm{dL})$ & 1.61 & 0.10 to 17.87 \\
\hline
\end{tabular}

Note: The continuous values are presented as medians, with ranges from minimum to maximum.

Abbreviations: AS, ankylosing spondylitis; BMI, body mass index; TNF, tumour necrosis factor; BASRI-hip, the Bath Ankylosing Spondylitis Radiology Hip Index; THA, total hip arthroplasty; ESR, erythrocyte sedimentation rate; CRP, C-reactive protein.

at onset and at surgery of hip involvement in AS patients were 18 years (range, 5 to 56 years) and 32 years (range, 19 to 67 years), respectively. The disease duration ranged from 0.5 to 40.3 years, with a median of 10.5 years. Of the AS patients with advanced hip involvement, 89.7\% $(n=218)$ were male, $10.5 \%(n=39)$ had a family history of rheumatism, $14.2 \%(\mathrm{n}=53)$ had a history of smoking, and $9.7 \%(n=36)$ were administrated with TNF inhibitors before. Bilateral onset in the hips was observed in $63.8 \%$ $(n=238)$ of the patients, while bilateral THA was performed in $67.3 \%(n=251)$ of them. The proportions of hips with BASRI-hip scores of 0 to 4 in the patients were $2.7 \% \quad(n=20), 5.2 \% \quad(n=39), 4.9 \% \quad(n=37), 42.0 \%$ $(n=313)$, and 45.2\% $(n=337)$, respectively. The ESR levels ranged from 1 to $108 \mathrm{~mm} / \mathrm{h}$ (median, $17 \mathrm{~mm} / \mathrm{h}$ ), and the CRP levels ranged from 0.10 to $17.87 \mathrm{mg} / \mathrm{dL}$ (median, $1.61 \mathrm{mg} / \mathrm{dL})$.

The age at surgery and body mass index (BMI) had no differences between patients with unilateral and bilateral THA $(\mathrm{P}>0.05)$. Male patients had a significant higher frequency of undergoing bilateral THA compared with female ones $(93.2 \%$ vs $86.9 \%, \mathrm{P}<0.05)$. The proportion of the patients who had bilateral onset in hips $(80.9 \%$ vs $28.7 \%$ ), administration of TNF inhibitors (17.2\% vs $6.0 \%$ ), flexion contracture in the hip (97.7\% vs $31.1 \%$ ), and a BASRI-hip score of $4(68.5 \%$ vs $29.5 \%)$ was significantly higher in those with bilateral THA than that in those with unilateral THA $(\mathrm{P}<0.05)$. Patients with bilateral THA experienced a significant longer disease duration than those with unilateral THA (median, 12 years; range 0.5 to 34.0 years vs median, 9 years; range, 0.5 to 40.3 years, $\mathrm{P}<0.05)$. Compared with the patients undergoing unilateral THA, the age at onset was slightly earlier (media, 18 years; range, 5 to 49 years vs median, 19 years; range 8 to 56 years) and the ESR (median, $19 \mathrm{~mm} / \mathrm{h}$; range 1 to $108 \mathrm{~mm} / \mathrm{h}$ vs median, $13 \mathrm{~mm} / \mathrm{h}$; range, 2 to $97 \mathrm{~mm} / \mathrm{h}$ ) and CRP (median, $1.69 \mathrm{mg} / \mathrm{dL}$; range, 0.10 to $17.87 \mathrm{mg} / \mathrm{dL}$ vs median, $1.49 \mathrm{mg} / \mathrm{dL}$; range, 0.10 to $10.30 \mathrm{mg} / \mathrm{dL}$ ) levels were higher in those undergoing bilateral THA, and the differences approached statistical significance $(\mathrm{P}=0.065,0.051$ and 0.073 , respectively) (Table 2).

The results of the logistic regression showed that factors related to bilateral THA were bilateral onset in hips $(\mathrm{OR}=10.177,95 \% \mathrm{CI}, 5.713$ to 18.130$)$, administration of TNF inhibitors $(\mathrm{OR}=0.346,95 \% \mathrm{CI}, 0.142$ to 0.838$)$, a BASRI-hip score of $4(\mathrm{OR}=4.133,95 \% \mathrm{CI}, 2.308$ to 7.400), and an ESR level ( $\mathrm{OR}=1.018$ for each unit increment, $95 \%$ CI,1.001 to 1.035 ) (Table 3 ).

\section{Discussion}

The effectiveness of THA has been proven in alleviating pain and improving function for AS patients with the endstage hip disease by a number of studies. ${ }^{9-12}$ However, revision surgery seems inevitable due to the limited life span of hip prostheses. ${ }^{9,13}$ The ideal systemic treatment strategies should be explored to prevent hip impairment, ${ }^{4}$ but it has not been completely achieved so far. By investigating the different outcomes in the end-stage hip involvement of AS, a study that aimed to reduce the amount or postpone the time of THA may be one of the feasible methods at present. Consequently, we identified that the risk factors associated with bilateral THA in AS patients were bilateral onset in hips, a BASRI-hip score of 4, and a higher level of ESR, while the protective factor related to that is the administration of TNF inhibitor.

The disease pattern of the onset in hip involvement is different in AS patients. Of the patients, it was observed 
Table 2 Comparison Between the Patients Who Underwent Unilateral and Bilateral THA

\begin{tabular}{|c|c|c|c|}
\hline & Unilateral THA $(n=\mid 22)$ & Bilateral THA $(n=25 I)$ & $\mathbf{P}$ \\
\hline \multicolumn{4}{|l|}{ Demographics } \\
\hline Age at surgery (years) & $3 I(19$ to 67$)$ & $32(19$ to 67$)$ & 0.911 \\
\hline Male (n, \%) & $106(86.9 \%)$ & $234(93.2 \%)$ & 0.043 \\
\hline BMI $\left(\mathrm{kg} / \mathrm{m}^{2}\right)$ & $22.66(14.42$ to 38.58$)$ & $22.49(\mid 11.87$ to 41.62$)$ & 0.533 \\
\hline \multicolumn{4}{|l|}{ Clinical characteristics } \\
\hline Age at onset (years) & $19(8$ to 56$)$ & $18(5$ to 49$)$ & 0.065 \\
\hline Bilateral onset in hips ( $n, \%)$ & $35(28.7 \%)$ & $203(80.9 \%)$ & $<0.001$ \\
\hline Disease duration (years) & $9(0.5$ to 40.3$)$ & $12(0.5$ to 34.0$)$ & 0.002 \\
\hline Administration of TNF inhibitors ( $\mathrm{n}, \%)$ & $2 \mathrm{I}(17.2 \%)$ & $15(6.0 \%)$ & 0.001 \\
\hline Family history of rheumatism $(\mathrm{n}, \%)$ & $10(8.2 \%)$ & $29(11.6 \%)$ & 0.320 \\
\hline Smoking history (n, \%) & $17(13.9 \%)$ & $36(14.3)$ & 0.916 \\
\hline Flexion contracture in the hip $(\mathrm{n}, \%)$ & $38(31.1 \%)$ & $126(97.7 \%)$ & 0.001 \\
\hline BASRI-hip score of $4(n, \%)$ & $36(29.5 \%)$ & $172(68.5 \%)$ & $<0.001$ \\
\hline \multicolumn{4}{|l|}{ Preoperative laboratory values } \\
\hline $\operatorname{ESR}(\mathrm{mm} / \mathrm{h})$ & $13(2$ to 97$)$ & $19(1$ to 108$)$ & 0.051 \\
\hline CRP (mg/dL) & $1.49(0.10$ to 10.30$)$ & $1.69(0.10$ to 17.87$)$ & 0.073 \\
\hline
\end{tabular}

Note: The continuous variables are presented as medians (minimum to maximum).

Abbreviations: THA, total hip arthroplasty; BMI, body mass index; TNF, tumour necrosis factor; BASRI-hip, the Bath Ankylosing Spondylitis Radiology Hip Index; ESR, erythrocyte sedimentation rate; CRP, C-reactive protein.

Table 3 Logistic Regression on Factors Associated with Bilateral THA in AS Patients with Advanced Hip Involvement

\begin{tabular}{|l|l|l|}
\hline Parameter & OR $(95 \% \mathbf{C l})$ & P value \\
\hline Male & $1.013(0.402$ to 2.549$)$ & 0.979 \\
Age at onset & $1.021(0.984$ to 1.059$)$ & 0.272 \\
Disease duration & $1.009(0.974$ to 1.045$)$ & 0.631 \\
Bilateral onset in hips & $10.177(5.713$ to 18.130$)$ & $<0.001$ \\
Administration of TNF inhibitors & $0.346(0.142$ to 0.838$)$ & 0.019 \\
Flexion contracture & $1.447(0.802$ to 2.612$)$ & 0.220 \\
BASRI-hip score of 4 & $4.133(2.308$ to 7.400$)$ & $<0.001$ \\
ESR & $1.018(1.001$ to 1.035$)$ & 0.043 \\
CRP & $0.920(0.788$ to 1.073$)$ & 0.287 \\
\hline
\end{tabular}

Abbreviations: THA, total hip arthroplasty; AS, ankylosing spondylitis; OR, odds ratio; Cl, confidence interval; TNF, tumour necrosis factor; BASRI, the Bath Ankylosing Spondylitis Radiology Hip Index; ESR, erythrocyte sedimentation rate; CRP, C-reactive protein.

that bilateral onset in hips accounted for $63.8 \%$, while bilateral THA was performed in $67.3 \%$ of them, and the latter result is close to that reported by Joshi et al. ${ }^{14}$ Moreover, the proportion of the patients who had bilateral onset in hips was significantly higher in patients with bilateral THA than that in unilateral THA $(80.9 \%$ vs $28.7 \%$ ). Consequently, it is not surprising that bilateral onset in hips is a risk factor associated with bilateral THA, and early intervention in these patients may help reduce the amount or delay the time of THA.

The BASRI-hip is the most commonly used method in studies for grading the severity of radiographic hip involvement in $\mathrm{AS}^{8}{ }^{8}$ A retrospective study has shown that the severity of radiographic hip involvement in AS is associated with bilateral hip involvement, the frequency of which is significantly different among the patients with varying BASRI-hip scores. ${ }^{15}$ Similarly, we found that a BASRI-hip score of 4 , representing more severe radiographic hip involvement, is a risk factor related to bilateral THA in AS patients. The previously reported prevalence of hip involvement in AS patients varies from 19 to $36 \%,{ }^{4,16,17}$ with bilateral involvement being more common. ${ }^{2,14}$ Thus, if one hip requires THA due to a hip score of 4 , the probability of the contralateral hip requiring THA will be greatly increased.

Data on the relationship between the inflammatory biomarkers and the severity of hip involvement remains 
inconsistent. One study reported that the ESR level decreased gradually with the severe grade of radiographic hip involvement in AS patients, ${ }^{15}$ while another study found that there was no difference in the ESR level between the early- and end-stage hip involvement. ${ }^{18}$ Our study found that a higher level of ESR is also a risk factor associated with bilateral THA in AS patients, and de Vries et al reported that ESR has a strong association with the Bath Ankylosing Spondylitis Disease Activity Index (BASDAI). ${ }^{19}$ Therefore, in clinical practice, if the ESR level continues to rise in AS patients with hip involvement, physicians should be aware of their possibility of developing into bilateral advanced hip involvement.

It has been shown that TNF inhibitors have the efficacy for improving symptoms and function clinically in the treatment of $\mathrm{AS}^{20,21}$ Vander Cruyssen et al concluded that hip involvement is one of the decisive factors for the application of TNF inhibitor by conducting a crosssectional cohort study. ${ }^{22}$ Several studies, evaluating the efficacy of anti-TNF therapy (etanercept) for treating hip involvement in AS, observed a clinical improvement of the hip symptoms and function, while found no significant change in the radiographic progression. ${ }^{23,24}$ However, Konsta $\mathrm{M}$ et al thought that the radiographic changes could not be observed within a short time frame, and they found that after continuous infliximab treatment with 2-10 years in AS patients, the radiographic progression of hip arthritis stabilized. ${ }^{25}$ Recent case series studies reported the efficacy of preventing structural damage progression in hips by anti-TNF therapy in AS patients. ${ }^{26,27}$ Data from the Norwegian Arthroplasty Register showed a trend towards a reduced frequency of hip replacement surgery in AS patients after the introduction of anti-TNF therapy. $^{28}$ Similarly, this study indicated that anti-TNF therapy can reduce the progression of hip involvement to bilateral THA. Therefore, we recommend that TNF inhibitors should be used once there is an onset of hip involvement, to reduce the amount or postpone the time of performing THA in AS patients.

Several limitations of the current study should also be noted. First, the course of treatment with TNF inhibitors cannot be unified in this retrospective study. Second, the delay in diagnosis may have influence on the administrating time of TNF inhibitors. Lastly, cost considerations may affect the application of TNF inhibitors.

In summary, bilateral THA is more common in AS patients with the end-stage hip disease and is considered to be more severe end-stage hip involvement compared with unilateral THA. There are differences in the clinical characteristics of the patients who underwent bilateral and unilateral THA. Anti-TNF therapy can reduce the progression of hip involvement to bilateral THA in AS patients, and a long-term cohort study is needed to evaluate the effect of therapeutic strategies in treating hip involvement in AS.

\section{Data Sharing Statement}

All data generated or analyzed during this study are included in this published article.

\section{Ethics Approval and Informed Consent}

This study was approved by the ethics committee of Chinese PLA general hospital (IRB number: S20210660-01, approval date 3/25/2021). Informed consents were not applicable due to the retrospective method and all data that could indicate the identity of the patients were kept confidential in this study. All methods were carried out in accordance with the Declaration of Helsinki.

\section{Acknowledgments}

The authors would like to thank Dr. Xiyue Chen, and Dr. Xiang Huang for their help with the data collection.

\section{Author Contributions}

All authors made substantial contributions to conception and design, acquisition of data, or analysis and interpretation of data; took part in drafting the article or revising it critically for important intellectual content; agreed to submit to the current journal; gave final approval of the version to be published; and agree to be accountable for all aspects of the work.

\section{Funding}

This work was supported by the National Key Research and Development Program of China [Grant numbers 2020YFC2004900].

\section{Disclosure}

The authors declare that they have no competing interests.

\section{References}

1. Marks JS, Hardinge K. Clinical and radiographic features of spondylitic hip disease. Ann Rheum Dis. 1979;38(4):332-336. doi:10.1136/ $\operatorname{ard} .38 .4 .332$ 
2. Dwosh IL, Resnick D, Becker MA. Hip involvement in ankylosing spondylitis. Arthritis Rheum. 1976;19(4):683-692. doi:10.1002/15290131(197607/08)19:4<683::aid-art1780190405>3.0.co;2-8

3. Vander Cruyssen B, Vastesaeger N, Collantes-Estévez E. Hip disease in ankylosing spondylitis. Curr Opin Rheumatol. 2013;25 (4):448-454. doi:10.1097/BOR.0b013e3283620e04

4. Vander Cruyssen B, Muñoz-Gomariz E, Font P, et al. Hip involvement in ankylosing spondylitis: epidemiology and risk factors associated with hip replacement surgery. Rheumatology. 2010;49 (1):73-81. doi:10.1093/rheumatology/kep174

5. Braun J, van den Berg R, Baraliakos X, et al. 2010 update of the ASAS/EULAR recommendations for the management of ankylosing spondylitis. Ann Rheum Dis. 2011;70(6):896-904. doi:10.1136/ ard.2011.151027

6. Lin D, Charalambous A, Hanna SA. Bilateral total hip arthroplasty in ankylosing spondylitis: a systematic review. EFORT Open Rev. 2019;4(7):476-481. doi:10.1302/2058-5241.4.180047

7. van der Linden S, Valkenburg HA, Cats A. Evaluation of diagnostic criteria for ankylosing spondylitis. A proposal for modification of the New York criteria. Arthritis Rheum. 1984;27(4):361-368. doi:10.1002/art.1780270401

8. MacKay K, Brophy S, Mack C, Doran M, Calin A. The development and validation of a radiographic grading system for the hip in ankylosing spondylitis: the bath ankylosing spondylitis radiology hip index. J Rheumatol. 2000;27(12):2866-2872.

9. Sochart DH, Porter ML. Long-term results of total hip replacement in young patients who had ankylosing spondylitis. Eighteen to thirty-year results with survivorship analysis. J Bone Joint Surg Am. 1997;79(8):1181-1189. doi:10.2106/00004623-199708000-00010

10. Brinker MR, Rosenberg AG, Kull L, Cox DD. Primary noncemented total hip arthroplasty in patients with ankylosing spondylitis. Clinical and radiographic results at an average follow-up period of 6 years. $J$ Arthroplasty. 1996;11(7):802-812. doi:10.1016/s0883-5403(96)80180-х

11. Bhan S, Pankaj A, Malhotra R. One- or two-stage bilateral total hip arthroplasty: a prospective, randomised, controlled study in an Asian population. J Bone Joint Surg Br. 2006;88(3):298-303. doi:10.1302/ 0301-620X.88B3.17048

12. Bangjian H, Peijian T, Ju L. Bilateral synchronous total hip arthroplasty for ankylosed hips. Int Orthop. 2012;36(4):697-701. doi:10.1007/s00264-011-1313-8

13. Bukowski BR, Clark NJ, Taunton MJ, Freedman BA, Berry DJ, Abdel MP. Revision Total Hip Arthroplasty in Patients With Ankylosing Spondylitis: long-Term Results. J Arthroplasty. 2020;35 (9):2573-2580. doi:10.1016/j.arth.2020.04.071

14. Joshi AB, Markovic L, Hardinge K, Murphy JCM. Total hip arthroplasty in ankylosing spondylitis: an analysis of $181 \mathrm{hips}$. J Arthroplasty. 2002;17(4):427-433. doi:10.1054/arth.2002.32170

15. Zhao J, Zheng W, Zhang C, Li J, Liu D, Xu W. Radiographic Hip Involvement in Ankylosing Spondylitis: factors Associated with Severe Hip Diseases. $J$ Rheumatol. 2015;42(1):106-110. doi:10.3899/jrheum. 140428
16. Wink F, Arends S, Maas F, et al. High prevalence of hip involvement and decrease in inflammatory ultrasound lesions during tumour necrosis factor$\alpha$ blocking therapy in ankylosing spondylitis. Rheumatology. 2019;58 (6):1040-1046. doi:10.1093/rheumatology/key382

17. Calin A, Elswood J. The relationship between pelvic, spinal and hip involvement in ankylosing spondylitis-one disease process or several? Br J Rheumatol. 1988;27(5):393-395. doi:10.1093/rheumatology/27.5.393

18. Chen D, Yuan S, Zhan Z, et al. Early-stage hip involvement in patients with ankylosing spondylitis: a Chinese study based on magnetic resonance imaging. Mod Rheumatol. 2016;26(6):933-939. doi: $10.3109 / 14397595.2016 .1153232$

19. de Vries MK, van Eijk IC, van der Horst-bruinsma IE, et al. Erythrocyte sedimentation rate, C-reactive protein level, and serum amyloid a protein for patient selection and monitoring of anti-tumor necrosis factor treatment in ankylosing spondylitis. Arthritis Rheum. 2009;61(11):1484-1490. doi:10.1002/art.24838

20. Maxwell LJ, Zochling J, Boonen A, et al. TNF-alpha inhibitors for ankylosing spondylitis. Cochrane Database Syst Rev. 2015;1(4): CD005468. doi:10.1002/14651858.CD005468.pub2

21. Callhoff J, Sieper J, Weiß A, Zink A, Listing J. Efficacy of TNF $\alpha$ blockers in patients with ankylosing spondylitis and non-radiographic axial spondyloarthritis: a meta-analysis. Ann Rheum Dis. 2015;74 (6):1241-1248. doi:10.1136/annrheumdis-2014-205322

22. Vander Cruyssen B, Ribbens C, Boonen A, et al. The epidemiology of ankylosing spondylitis and the commencement of anti-TNF therapy in daily rheumatology practice. Ann Rheum Dis. 2007;66 (8):1072-1077. doi:10.1136/ard.2006.064543

23. Lian F, Yang X, Liang L, et al. Treatment efficacy of etanercept and MTX combination therapy for ankylosing spondylitis hip joint lesion in Chinese population. Rheumatol Int. 2012;32(6):1663-1667. doi:10.1007/s00296-011-1844-8

24. Wang D, Ma L, Wu D. Efficacy of etanercept in ankylosing spondylitis hip lesions. Joint Bone Spine. 2011;78(5):531-532. doi:10.1016/ j.jbspin.2011.03.023

25. Konsta M, Sfikakis PP, Bournia VK, Karras D, Iliopoulos A. Absence of radiographic progression of hip arthritis during infliximab treatment for ankylosing spondylitis. Clin Rheumatol. 2013;32 (8):1229-1232. doi:10.1007/s10067-013-2263-X

26. Song R, Chung SW, Lee S-H. Radiographic Evidence of Hip Joint Recovery in Patients with Ankylosing Spondylitis after Treatment with Anti-tumor Necrosis Factor Agents: a Case Series. J Rheumatol. 2017;44(11):1759-1760. doi:10.3899/jrheum.161401

27. Rocha FAC, Pinto ACMD, Lopes JR, Deodhar A. Tumor necrosis factor inhibitors prevent structural damage in hips in ankylosing spondylitis-time to reconsider treatment guidelines? A case series and review of literature. Clin Rheumatol. 2020. doi:10.1007/ s10067-020-05519-0

28. Nystad TW, Furnes O, Havelin LI, Skredderstuen AK, Lie SA, Fevang B-TS. Hip replacement surgery in patients with ankylosing spondylitis. Ann Rheum Dis. 2014;73(6):1194-1197. doi:10.1136/ annrheumdis-2013-203963
International Journal of General Medicine

\section{Publish your work in this journal}

The International Journal of General Medicine is an international, peer-reviewed open-access journal that focuses on general and internal medicine, pathogenesis, epidemiology, diagnosis, monitoring and treatment protocols. The journal is characterized by the rapid reporting of reviews, original research and clinical studies across all disease areas. The manuscript management system is completely online and includes a very quick and fair peer-review system, which is all easy to use. Visit http://www.dovepress.com/ testimonials.php to read real quotes from published authors. 